\title{
ALIMENTO SEGURO EM FOCO CUIDADOS COM A HIGIENE DE FRUTAS E HORTALIÇAS PARA A PREVENÇÃO DE SURTOS ALIMENTARES
}

ORGANIZADORA

Simone Kelly Rodrigues Lima 


\section{ALIMENTO SEGURO EM FOCO CUIDADOS COM A HIGIENE DE FRUTAS E HORTALIÇAS PARA A PREVENÇÃO DE SURTOS ALIMENTARES}

ORGANIZADORA

Simone Kelly Rodrigues Lima 


\title{
ZAMPLLA
}

2021 - Editora Amplla

Copyright (C) Editora Amplla

Editor Chefe: Leonardo Pereira Tavares

Design da Capa: Editora Amplla

Projeto Gráfico e Diagramação: Higor Costa de Brito

Alimento seguro em foco: cuidados com a higiene de frutas e hortaliças para a prevenção de surtos alimentares está licenciado sob CC BY 4.0.

\begin{abstract}
(c) (i)
Esta licença exige que as reutilizações deem crédito aos criadores. Ele permite que os reutilizadores distribuam, remixem, adaptem e construam o material em qualquer meio ou formato, mesmo para fins comerciais.

O conteúdo da obra e seus dados em sua forma, correção e confiabilidade são de responsabilidade exclusiva dos autores, não representando a posição oficial da Editora Amplla. É permitido o download da obra e o compartilhamento desde que sejam atribuídos créditos aos autores. Todos os direitos para esta edição foram cedidos à Editora Amplla.
\end{abstract}

ISBN: 978-65-88332-56-6

DOI: $10.51859 /$ amplla.asf566.1121-0

Editora Amplla

Campina Grande - PB - Brasil contato@ampllaeditora.com.br www.ampllaeditora.com.br 


\section{CONSELHO EDITORIAL}

Andréia Monique Lermen - Universidade Federal do Rio Grande do Sul

Bergson Rodrigo Siqueira de Melo - Universidade Estadual do Ceará

Bruna Beatriz da Rocha - Instituto Federal do Sudeste de Minas Gerais

Caio César Costa Santos - Universidade Federal de Sergipe

Carina Alexandra Rondini - Universidade Estadual Paulista

Carla Caroline Alves Carvalho - Universidade Federal de Campina Grande

Carlos Augusto Trojaner - Prefeitura de Venâncio Aires

Cícero Batista do Nascimento Filho - Universidade

Federal do Ceará

Clécio Danilo Dias da Silva - Universidade Federal do Rio Grande do Norte

Daniela de Freitas Lima - Universidade Federal de Campina Grande

Denise Barguil Nepomuceno - Universidade Federal de Minas Gerais

Dylan Ávila Alves - Instituto Federal Goiano

Edson Lourenço da Silva - Instituto Federal de Educação, Ciência e Tecnologia do Piauí

Elane da Silva Barbosa - Universidade Estadual do Ceará Érica Rios de Carvalho - Universidade Católica do Salvador

Gilberto de Melo Junior - Instituto Federal do Pará

Higor Costa de Brito - Universidade Federal de Campina Grande

Italan Carneiro Bezerra - Instituto Federal da Paraíba

Ivo Batista Conde - Universidade Estadual do Ceará

Jessica Wanderley Souza do Nascimento - Instituto de Especialização do Amazonas

João Henriques de Sousa Júnior - Universidade Federal de Santa Catarina

João Manoel Da Silva - Universidade Federal de Alagoas João Vitor Andrade - Universidade de São Paulo

Joilson Silva de Sousa - Instituto Federal do Rio Grande do Norte

José Cândido Rodrigues Neto - Universidade Estadual da Paraíba

Jose Henrique de Lacerda Furtado - Instituto Federal do Rio de Janeiro

Josenita Luiz da Silva - Faculdade Frassinetti do Recife Karina de Araújo Dias - SME/Prefeitura Municipal de Florianópolis

Laíze Lantyer Luz - Universidade Católica do Salvador Lindon Johnson Pontes Portela - Universidade Federal do Oeste do Pará

Lucas Capita Quarto - Universidade Federal do Oeste do Pará

Luciana de Jesus Botelho Sodré dos Santos - Universidade Estadual do Maranhão

Luís Paulo Souza e Souza - Universidade Federal do Amazonas

Luiza Catarina Sobreira de Souza - Faculdade de Ciências Humanas do Sertão Central

Manoel Mariano Neto da Silva - Universidade Federal de Campina Grande
Marcelo Alves Pereira Eufrasio - Centro Universitário Unifacisa

Marcelo Williams Oliveira de Souza - Universidade Federal do Pará

Marcus Vinicius Peralva Santos - Universidade Federal da Bahia

Marina Magalhães de Morais - Universidade Federal de Campina Grande

Nadja Maria Mourão - Universidade do Estado de Minas Gerais

Natan Galves Santana - Universidade Paranaense

Nathalia Bezerra da Silva Ferreira - Universidade do Estado do Rio Grande do Norte

Neide Kazue Sakugawa Shinohara - Universidade Federal Rural de Pernambuco

Neudson Johnson Martinho - Faculdade de Medicina da Universidade Federal de Mato Grosso

Patrícia Appelt - Universidade Tecnológica Federal do Paraná

Paulo Henrique Matos de Jesus - Universidade Federal do Maranhão

Rafael Rodrigues Gomides - Faculdade de Quatro Marcos Reângela Cíntia Rodrigues de Oliveira Lima Universidade Federal do Ceará

Rebeca Freitas Ivanicska - Universidade Federal de Lavras

Ricardo Leoni Gonçalves Bastos - Universidade Federal do Ceará

Rodrigo da Rosa Pereira - Universidade Federal do Rio Grande

Sabrynna Brito Oliveira - Universidade Federal de Minas Gerais

Samuel Miranda Mattos - Universidade Estadual do Ceará Shirley Santos Nascimento - Universidade Estadual Do Sudoeste Da Bahia

Silvana Carloto Andres - Universidade Federal de Santa Maria

Silvio de Almeida Junior - Universidade de Franca

Tatiana Paschoalette Rodrigues Bachur - Universidade Estadual do Ceará

Telma Regina Stroparo - Universidade Estadual do Centro-Oeste

Thayla Amorim Santino - Universidade Federal do Rio Grande do Norte

Virgínia Maia de Araújo Oliveira - Instituto Federal da Paraíba

Virginia Tomaz Machado - Faculdade Santa Maria de Cajazeiras

Walmir Fernandes Pereira - Miami University of Science and Technology

Wanessa Dunga de Assis - Universidade Federal de Campina Grande

Wellington Alves Silva - Universidade Estadual de Roraima

Yáscara Maia Araújo de Brito - Universidade Federal de Campina Grande

Yasmin da Silva Santos - Fundação Oswaldo Cruz

Yuciara Barbosa Costa Ferreira - Universidade Federal de Campina Grande 


\section{Z ZAMPLLA}

\section{1 - Editora Amplla}

Copyright (C) Editora Amplla

Editor Chefe: Leonardo Pereira Tavares

Design da Capa: Editora Amplla

Projeto Gráfico e Diagramação: Higor Costa de Brito

Alimento seguro em foco [livro eletrônico]: cuidados com a higiene de frutas e hortaliças para a prevenção de surtos alimentares / organização Simone Kelly Rodrigues Lima. Campina Grande : Editora Amplla, 2021.

$32 \mathrm{p}$.

Formato: PDF

ISBN : $978-65-88332-56-6$

1. Doenças de origem alimentar 2. Alimentos - Manuseio Medidas de segurança II. Título

$\mathrm{CDD}-641.4$

\section{Índices para catálogo sistemático:}

1. Alimentos 641.4

Editora Amplla

Campina Grande - PB - Brasil contato@ampllaeditora.com.br www.ampllaeditora.com.br 


\section{DEDICAMOS}

Aos que acreditam que a educação e a ciência podem construir um mundo melhor, seja pelas idéias ou pelas ações que possibilitam as práticas para o bem comum.

Aos que trabalham, apoiam e acreditam que pela união de esforços, podemos chegar a alternativas para que um dia, ninguém tenha o caminho da vida ceifado porque se alimentou, ou porque deixou de se alimentar.

A todos os estudantes, profissionais e entusiastas dessa jornada que leva ao conhecimento e nos revelam caminhos.

À todos aqueles que seguram a nossa mão durante essa caminhada. 


\section{APRESENTAÇÃO}

Uma alimentação de qualidade carrega a compreensão de que aliados à quantidade, adequação e acesso, um alimento precisa ser seguro para consumo do ponto de vista da inocuidade, carregando a garantia de que esse esteja livre de micro-organismos que possam causar doenças e trazer prejuízos à saúde.

Embora os cuidados com a higiene não sejam algo novo, a segurança dos alimentos ainda persiste como um dos principais problemas globais de saúde pública e tem demandado um esforço constante de vários setores ao longo da cadeia produtiva. As doenças de origem alimentar (DOAs) ainda são responsáveis por óbitos e adoecimentos evitáveis, em que o cumprimento de requisitos básicos de higiene poderiam garantir um alimento apto para consumo, principalmente daqueles produtos que são consumidos crus, como frutas e hortaliças.

Diante de tantos desafios, a comunidade científica, autoridades em segurança de alimentos e os profissionais do setor buscam incessantemente diretrizes e orientações capazes de diminuir os riscos para o consumidor, incluindo os cuidados com a chegada do produto nos domicílios, os quais têm sido apontados como um dos principais locais de incidência das DOAs.

Nesse contexto, este livro traz, em dois capítulos, uma revisão da literatura sobre temas relacionados aos aspectos higiênicos que interferem na segurança do consumo de frutas e hortaliças, abordando aspectos relacionados aos pontos de riscos da cadeia, principais bactérias patogênicas associadas aos surtos notificados, sintomas, período de incubação, legislação vigente e por fim, recomendações de limpeza e sanitização dos produtos na chegada ao seu destino final: Nossa casa. 
"O que somos é um presente que a vida nos dá. o que nós seremos é um presente que daremos à vida." Herbert de Souza (Betinho) 


\section{SUMÁRIO}

CAPÍTULO | - FATORES QUE CONTRIBUEM PARA A CONTAMINAÇÃO DE FRUTAS E HORTALIÇAS POR BACTÉRIAS PATOGÊNICAS 


\section{CAṔTULO I}

\section{FATORES QUE CONTRIBUEM PARA A CONTAMINAÇÃO DE FRUTAS E HORTALIÇAS POR BACTÉRIAS PATOGÊNICAS}

DOI: 10.51859/amplla.asf566.1121-1

Keciane da Conceição Ferreira ${ }^{1}$

Derlani da Silva Soares ${ }^{1}$

Gleice Ferreira da Costa da Cruz ${ }^{1}$

Glaucia Ferreira da Costa da $\mathrm{Cruz}^{1}$

Simone Kelly Rodrigues Lima ${ }^{2}$

\footnotetext{
${ }^{1}$ Graduanda do Curso Superior de Tecnologia de Alimentos. Instituto Federal de Educação, Ciência e Tecnologia do Maranhão - IFMA/Campus Bacabal

${ }^{2}$ Mestra em Alimentos e Nutrição. Docente do Curso de Tecnologia de Alimentos. Instituto Federal de Educação, Ciência e Tecnologia do Maranhão - IFMA/Campus Bacabal
}

\section{RESUMO}

As doenças de origem alimentar são caracterizadas pela ingestão de alimentos e/ou água, com a presença de contaminantes (químicos, físicos ou biológicos) que chegam até o organismo e afetam a saúde de forma individual ou em grupo. Entre os principais causadores dessas doenças, destacam-se os micro-organismos e suas toxinas, que podem contaminar os alimentos durante toda a cadeia produtiva, podendo chegar ao consumidor principalmente quando os processos de manipulação e higiene são realizados de forma inadequada. A preocupação com os processos higiênicos merece especial atenção quando os alimentos são para consumo in natura, como ocorre habitualmente com frutas e hortaliças. Comumente são relatados a presença de contaminação desses alimentos por bactérias patogênicas, especialmente Salmonella spp., Listeria spp., Escherichia coli e estafilococos aureus. Desta forma, esta pesquisa buscou identificar os principais fatores que contribuem para a contaminação de frutas e hortaliças nas diferentes fases da cadeia produtiva por meio de um estudo de revisão, com foco nas bactérias patogênicas. As informações reunidas contemplam ainda uma discussão sobre a legislação vigente sobre o tema e sua importância para o fornecimento de um alimento seguro para consumo.

Palavras-chave: Frutas e hortaliças. Segurança dos alimentos. Bactérias patogênicas.

\section{INTRODUÇÃO}

As temáticas que abordam a segurança dos alimentos vem sendo alvo frequente de discussões no âmbito nacional e internacional, pois estão diretamente 
relacionadas à saúde pública. 0 termo segurança dos alimentos refere-se à garantia de que o alimento disponibilizado não causará nenhum efeito adverso à saúde do consumidor. Assim, o alimento é considerado seguro ou inócuo quando ocorre a implementação de um conjunto de medidas, realizadas durante toda cadeia produtiva, com o objetivo de aumentar a qualidade dos alimentos e evitar a entrada de qualquer perigo capaz de provocar danos aos consumidores (BREGOLIN, 2018).

Desta forma, entende-se que a chamada inocuidade dos alimentos trata da incapacidade dos mesmos funcionarem como possíveis transmissores de perigos que resultam em doenças de origem alimentar (DOA). De acordo com o Ministério da Saúde (MS), entre os anos de 2008 a 2018 foram registrados no Brasil, 6.809 casos de surtos de doenças alimentares, que ocasionaram 99 óbitos e deixaram 120.584 doentes. As regiões que apresentaram maior número de casos foram o sudeste e nordeste com $41,62 \%$ e $23,68 \%$ do total de casos, respectivamente (SOUZA, 2019).

As doenças de origem alimentar são caracterizadas pela ingestão de alimentos e/ou água, com a presença de contaminantes (químicos, físicos ou biológicos) que chegam até o organismo e afetam a saúde de forma individual ou em grupo. De acordo Melo et al (2018) atualmente são conhecidas mais 250 doenças alimentares que provocam graves problemas de saúde.

Dentre os principais causadores dessas doenças, destacam-se as bactérias patogênicas e suas toxinas, que podem contaminar os alimentos em qualquer fase da cadeia produtiva, principalmente nos processos de manipulação, quando a higienização é realizada de modo inadequado e torna-se ineficaz (GANGLIONE, 2015). Os cuidados nessas etapas devem ser ainda maiores com os alimentos consumidos in natura, como as frutas e hortaliças, considerando também que estes produtos obtiveram um grande aumento no consumo, em virtude do maior conhecimento sobre qualidade e da constante busca da sociedade moderna por hábitos alimentares mais saudáveis (Da SILVA et al, 2019).

Entre os agentes biológicos mais comuns em frutas e hortaliças, as bactérias patogênicas são as que mais se sobressaem, especialmente a Salmonella spp., Listeria spp., Escherichia coli e estafilococos aureus. A presença desses microorganismos nos vegetais sofre influência de vários fatores, porém está fortemente relacionada às condições higiênico-sanitárias impróprias durante a produção e 
distribuição desses alimentos. Segundo a Agência Nacional de Vigilância Sanitária (ANVISA) a Salmonela é uma das principais responsáveis pelo aumento dos surtos de doenças alimentares. A ocorrência desta bactéria em frutas e hortaliças indica que houve má higienização desses alimentos ou falta de hábitos higiênicos dos manipuladores. O consumo de alimentos contaminados por Salmonella provoca sintomas como diarreia, febre, calafrios e dor abdominal (BERTOLINO, 2010).

Estas consequências danosas à saúde e a maior incidência de doenças de origem alimentar reforçam a necessidade da implementação correta das medidas de controle e fiscalização, visando reduzir os riscos de contaminação dos alimentos, principalmente dos vegetais. A ANVISA, através do Ministério da Saúde (MS), estabelece resoluções nas quais estão descritos os procedimentos que devem ser implantados pelos estabelecimentos produtores e industrializadores de alimentos com destaque a RDC N² 216 de 2004 , que dispões sobre a elaboração do checklist (lista de verificação) das Boas Práticas de Fabricação (BPF), não dispensando especial atenção aos requisitos básicos para os Procedimentos Operacionais Padronizados (POP) e para a Análise de Perigos e Pontos Críticos de Controle (APPCC). Estas medidas, quando adotadas em conjunto, reduzem significativamente o risco de contaminação aumentando a qualidade dos alimentos (OBARA, 2018).

Diante dos fatos mencionados, fica evidente a importância da adoção de práticas higiênicas corretas, capazes de minimizar a contaminação por microorganismos patogênicos durante a produção de alimentos consumidos in natura

\section{SEGURANÇA DOS ALIMENTOS}

Nos últimos anos, a alimentação tornou- se uma das grandes preocupações em todo o mundo, uma vez que este tema tem gerado vários desafios em virtude da necessidade de adequação ao constante crescimento da população mundial e a produção de alimentos. Em países como o Brasil, a preocupação é maior, pois existem milhões de pessoas famintas, para as quais, os quesitos relacionados a quantidade muitas vezes se sobrepõem aos quesitos de qualidade para os alimentos disponíveis para consumo. Assim, a segurança dos alimentos deve ser observada por todos os envolvidos ao longo da cadeia de produção, comercialização e consumo, 
pois a ausência da segurança alimentar pode gerar consequências danosas ao consumidor final (SANTOS et al., 2019).

Desta forma, a segurança dos alimentos, tem gerado quadros preocupantes em termos de economia e saúde pública, afetando diretamente o setor alimentício. De modo geral, esse termo define uma alimentação livre ou isenta de qualquer tipo de riscos para a saúde, porém, o número crescente de alimentos contaminados, transformou a segurança dos alimentos em um alvo frequente de debates que abordam diversas áreas e interesses de um país (BIANCHINI et al., 2013).

0 conceito de segurança dos alimentos envolve uma série de medidas que objetivam proporcionar maior qualidade aos produtos, além de controlar a entrada de qualquer agente que possa oferecer perigo à saúde ou integridade física do consumidor. Assim, o alimento será considerado seguro quando houver um controle sobre todas as etapas da cadeia produtiva, incluindo os processos que ocorrem desde o campo (pré-colheita) até a chegada do produto final na mesa do consumidor (VINHOLIS e AZEVEDO, 2002).

É importante salientar que o termo "Alimento Seguro" ainda não possui uma definição clara e universalmente aceita, pois trata-se de um termo bastante relativo, que associa o risco em um nível aceitável a uma população ou grupo específico. De modo geral o alimento seguro ou inócuo é aquele que possuem níveis aceitáveis ou é livre de contaminantes, sejam eles de ordem física, química ou biológica, sendo incapaz de oferecer qualquer tipo de risco ou danos à saúde. Desta forma, a inocuidade dos alimentos está relacionada à incapacidade dos mesmos atuarem como agentes transmissores de perigos que geram potenciais causadores de Doenças Vinculadas a Alimentos (DVA's). Esta inocuidade precisa ser reafirmada com utilização de medidas de fiscalização, regulamentação e educação de modo integrado e eficiente em toda cadeia produtiva de alimentos (SÃO JOSÉ, 2017).

Neste contexto, novos desafios têm surgido para a segurança dos alimentos, estes decorrem da adaptação dos micro-organismos aos mecanismos de proteção mais convencionais e as novas tecnologias juntamente com as variações ecológicas e o aumento mundial do comércio de alimentos. Além disso, essas questões desafiadoras também são resultantes dos novos hábitos alimentares, provenientes de consumidores cada vez mais conscientes, com o conhecimento que a segurança dos alimentos e os sistemas que as impulsionam deve ser implantada em âmbito 
nacional e global. Diante disso, a Organização Mundial da Saúde (OMS) tem alertado sobre a importância de se reduzir a contaminação de alimentos por agentes biológicos capazes de causar doenças (SPERS, 2003).

\section{FRUTAS E HORTALIÇAS NO CONTEXTO DAS DOENÇAS DE ORIGEM ALIMENTAR - DOA'S}

A contaminação microbiológica dos alimentos pode ocorrer durante todas as etapas de produção e distribuição dos alimentos. A preocupação é maior em relação aos alimentos que não serão submetidos a nenhum tipo cocção ou processamento, como é caso das frutas e hortaliças consumidos in natura, cuja a grande quantidade de nutrientes e elevada atividade de água é fator determinante para a proliferação de micro organismos (MARINHO et al., 2015).

Atualmente são conhecidos diversos tipos de doenças alimentares, em sua maioria ocasionada por microorganismos patogênicos. Estes, são capazes de ocasionar grandes perdas para o produtor ou fabricantes de alimentos e graves problemas de saúde pública. Os surtos ocasionados por doenças vinculadas a alimentos podem ocorrer após o consumo do alimento contaminado por microorganismos patogênicos ou suas toxinas, quando uma ou mais pessoas apresentam os mesmos sintomas. Dentre os sintomas mais comuns das DOA's estão diarreia, dor de estômago, náuseas, vômitos e em alguns casos febre ( OLIVEIRA et al., 2010).

Para garantir a segurança e a qualidade desses alimentos é preciso que todas as etapas da cadeia produtiva sejam devidamente executadas dentro dos padrões de boas práticas de higiene, pois caso haja uma falha em algumas destas etapas esses produtos podem ser contaminados. 0 contágio de frutas e hortaliças pode acontecer por meio do ambiente de produção, transporte, armazenamento ou manipulação inadequada. Muitos fatores contribuem para que os alimentos in natura deixem de ser seguros para o consumo, dentre eles incluem: etapas pré-colheita e pós-colheita, uso de água contaminada para irrigação, adubação do solo com estercos, instalações deficientes, manipuladores portadores de microrganismo patogênicos, equipamentos e utensílios mal lavados, má higiene dos manipuladores e equipamentos de difícil higienização e manutenção (FERREIRA, 2006). 
As etapas em que ocorrem os processos de manipulação e higienização, o transporte e comercialização são as mais preocupantes principalmente para as frutas e hortaliças que são consumidas comumente de forma natural. Esta preocupação está relacionada a falta de práticas higiênicas corretas e as frequentes mudanças conceituais e técnicas do controle higiênico-sanitário, pois tais modificações são provocados pelos novos conhecimentos relacionados aos microorganismo que causam doenças alimentares atrelado ao aparecimento constante de novas cepas microbianas que possuem grande adaptação aos métodos mais convencionais e antigos utilizados como mecanismos de proteção (SÃO JOSÉ et al., 2016).

Os dados divulgados pela Agência Nacional de Vigilância Sanitária (ANVISA), demonstram que os agentes biológicos são os principais causadores das doenças de origem alimentar, em especial, as bactérias patogênicas, que são responsáveis pela maioria surtos de doenças vinculadas à alimentos no Brasil apresentando cerca de $63 \%$ dos casos.

Assim, devido a grande diversificação das frutas e hortaliças é importantíssimo assegurar que tais alimentos sejam seguros, para isto, é necessário atentar para as condições de higiene, utilizando uma abordagem mais sistemática e proativa sobre este tema, objetivando minimizar os riscos de contaminações, que podem ocorrer desde o campo até a mesa do consumidor (TONDO et al., 2015).

As hortaliças apresentam em sua microbiota natural uma carga microbiana que provém do ambiente, sendo influenciada pela estrutura da planta, técnicas de cultivo, transporte e armazenamento (SANTAREM et al., 2012).

Em uma pesquisa realizada em Juazeiro do Norte-CE no ano de 2017, em que foram realizadas análises bacteriológicas de 50 amostras de frutas e hortaliças em mercados de hortifrutis públicos e privados, foram observados presença de bactérias, com destaque para o Bacillus spp., Stapylococcus aureus, Escherichia coli e Klebsiella spp., detectados e isolados em todas as amostras. Cabe ressaltar que embora qualquer patógeno possa se tornar problema potencial em frutas e hortaliças, a Salmonella spp. assume relevância especial para a saúde pública (CORREIA et al, 2017).

A transmissão da bactéria Salmonella acontece pela ingestão de alimentos ou água contaminados. Trata-se, de uma disseminação fecal-oral, quando pessoas 
infectadas entram em contato com alimentos sem a devida proteção, repassando o micro-organismo. Sua presença é comum em frutos como melão, alface e tomates (TEIXEIRA et al., 2013 ). Outro tipo de bactéria que também pode ser encontrada em frutas e hortaliças é a Listeria. Embora não seja muito observada no Brasil, essa bactéria fez várias vítimas nos Estados Unidos através do consumo de melão e maçãs caramelizadas. A infecção pode ser muitas vezes assintomática, no entanto os sintomas podem aparecer em crianças, gestantes, idosos e portadores de doenças crônicas, Os sintomas iniciais podem ser confundidos com os da gripe, uma vez que há febre, dor no corpo e calafrios (MENEZES et al, 2013).

Frutas e hortaliças também podem ser contaminadas, antes do consumo, por outras bactérias como: Shigella spp., Campylobacter spp., Yersinia enterocolitica, Clostridium spp e Vibrio spp. As doenças causadas por esses microrganismos produzem principalmente sintomas como dores abdominais, vômitos frequentes, dor de cabeça, náuseas constantes, cansaço excessivo e febre (SOUSA , 2017).

Diante disso é possível entender que a contaminação das frutas e hortaliças podem causar sérios danos à saúde da população, por esse motivo é de extrema importância que sejam tomados cuidados redobrados com a manipulação e os processos de higiene desses produtos com intuito de garantir um alimento seguro e consequentemente a saúde dos consumidores.

\section{LEGISLAÇÃO NACIONAL}

As boas práticas de fabricação (BPF), análise de perigo, pontos críticos de controle (APPCC) e os Procedimentos Operacionais Padronizados (POPS) são um conjunto de requisitos e análise crítica do ambiente de produção que se estende por toda a cadeia de fornecimento até o consumidor final, objetivando à redução dos perigos de infecção e intoxicação alimentar, seja ela aguda ou crônica (ROUGEMONT, 2007).

Diante disso a ANVISA, instituiu algumas legislações que tratam sobre estas medidas que devem ser tomadas a fim de garantir a qualidade e a segurança, reduzindo o risco de contaminação das frutas e hortaliças para consumo in natura, minimamente processadas ou processadas. Dentre essas legislações podemos citar:

I. A Resolução no 352 de 23 de Dezembro de 2002, que dispõe sobre o Regulamento Técnico de Boas Práticas de Fabricação para Estabelecimentos 
Produtores/Industrializadores de Frutas e ou Hortaliças em Conserva e objetiva estabelecer as instruções sequenciais para a realização de operações rotineiras e específicas na produção, armazenamento e transporte desses produtos (BRASIL, 2003).

II. A RDC $\mathrm{N}^{\circ} 331$ de 23 de dezembro de 2019 que trata sobre padrões microbiológicos dos alimentos e sua aplicação, que passaram a vigorar em substituição a instrução Normativa MAPA/SARC № 12 de 29 de novembro de 2001. A RDC N³31, de 23 de dezembro de 2019, abrange toda cadeia produtiva, tratando dos padrões microbiológicos dos alimentos e a aplicação dos mesmos. Juntamente com a Instrução Normativa n⿳0 60, de 23 de dezembro de 2019, estabelece os novos padrões microbiológicos de alimentos, com critérios que definem a aceitabilidade de um lote ou processo (BRASIL, 2019). Além disso, conforme ainda a RDC $331 / 2019$, a cadeia produtiva e os setores nela envolvidos são responsáveis por realizar avaliações periódicas, quanto à adequação de processos para atendimento aos padrões e também determinar uma frequência das análises, assegurando que os alimentos atendam os padrões microbiológicos estabelecidos pela IN 60/2019, e estejam em conformidade com as boas práticas de fabricação (BPF) e outros programas de controle de qualidade como APPCC e POP (BRASIL, 2019).

Entre as principais modificações observadas para frutas e hortaliças na nova legislação, especificamente nos padrões microbiológicos apresentados na IN 60/2019, destaca-se a substituição dos Coliformes $45^{\circ}$ (abordados na IN 12/2001) pela pesquisa de Escherichia coli nas avaliações da frutas e hortaliças, tendo em vista que este microrganismo é comumente associado a surtos de DVAs. De acordo com Souza (2019), entre 2008 a 2018 a E. Coli foi o agente etiológico mais detectado em surtos de doenças vinculadas à alimentos no Brasil apresentando $23,4 \%$ do total dos casos. Vale ressaltar, que todas mudanças realizadas nesta legislação tem como objetivos atender as necessidades sanitárias em âmbito nacional e internacional.

Portanto, assegurar a qualidade das frutas e hortaliças por meio das normas vigentes e trabalhar de forma eficiente são os principais pontos que irão influenciar na satisfação do cliente, dessa maneira, seja através de ações individuais ou coletivas é de extrema importância que sejam seguido a aplicação das normas para evitar 
circunstâncias que coloquem em risco à saúde através dos alimentos, buscando a promoção da segurança alimentar da população.

\section{CONSIDERAÇÕES FINAIS}

Diante do exposto, ressalta-se que os processos higiênicos realizados de forma inadequada e a falta de práticas higiênicas dos manipuladores são os fatores que mais influenciam a contaminação por bactérias patogênicas, tendo em vista que as bactérias mais comuns nesses alimentos indicam condições higiênico-sanitárias insatisfatória durante a cadeia produtiva, principalmente nas etapas de manipulação, higienização, transporte e comercialização destes produtos.

Também recomenda-se fortemente a implementação de processos e práticas que objetivam reduzir o risco de contaminação durante a cadeia produtiva dos vegetais, pois é certo que a adoção das BPF, POP e APPCC, proporcionaram maior qualidade as frutas e hortaliças, minimizando o risco de contaminação e impedindo que estes alimentos atuem como potenciais transmissores de doenças alimentares. Além disso, é essencial que sejam realizadas análises frequentes nesses vegetais durante todas as etapas da cadeia produtiva para garantir que os mesmos cumpram os padrões microbiológicos exigidos pela legislação vigente.

\section{REFERÊNCIAS}

BERTOLINO, MT. Gerenciamento da Qualidade na Indústria de Alimentos: ênfase na segurança de alimentos. Artmed, p. 320, Porto Alegre, 2010.

BIANCHINI, A. et al. Microbiologia da Segurança dos Alimentos. Artmed , $2^{\circ}$ edição p. 277-385, São Paulo, 2013.

BRASIL. Ministério da Saúde-MS. Agência Nacional de Vigilância Sanitária - ANVISA. RESOLUÇÃO DE DIRETORIA COLEGIADA- RDC N² 216, 15 DE SETEMBRO DE 2004. Abrange os procedimentos que devem ser adotados nos serviços de alimentação, a fim de garantir as condições Higiênico-sanitárias do alimento preparado Disponível em: https://bvsms.saude.gov.br/bvs/saudelegis/anvisa/2004/res0216_15_09_ 2004.html. Acesso em: 14 de fev. 2021

BRASIL. Ministério da Saúde-MS. Agência Nacional de Vigilância Sanitária - ANVISA. RESOLUÇÃO DE DIRETORIA COLEGIADA-RDC N 352, DE 23 DE DEZEMBRO DE 2002. Dispõe sobre o Regulamento Técnico de Boas Práticas de 
Fabricação para Estabelecimentos Produtores/Industrializadores de Frutas e ou Hortaliças em Conserva e a Lista de Verificação das Boas Práticas de Fabricação para Estabelecimentos Produtores/Industrializadores de Frutas e ou Hortaliças em Conserva. Disponível em: http://bvsms.saude.gov.br/bvs/saudelegis/anvisa/2002/rdc0352_23_12_2 002.html. Acesso em: 14 de fev.2021.

BRASIL. Ministério da Saúde-MS. Agência Nacional de Vigilância Sanitária - ANVISA. RESOLUÇÃO DE DIRETORIA COLEGIADA - RDC № 12, DE 02 DE JANEIRO DE 2001. Dispõe sobre os critérios e padrões microbiológicos para alimentos, indispensáveis para a avaliação das Boas Práticas lie Produção de Alimentos e Prestação de Serviços e da aplicação do Sistema de Análise de Perigos e Pontos Críticos de Controle (APPCC/HACCP). Disponível em: <http://www.editoralex.com.br/doc_308643_resolucao_n_12_de_marco_de _1978.aspx>. Acesso em: 11 de fev.2021.

BRASIL. Ministério da saúde-MS. Agência Nacional de Vigilância Sanitária - ANVISA. RESOLUÇÃO DE DIRETORIA COLEGIADA - RDC № 331, DE 23 DE DEZEMBRO DE 2019. Dispõe sobre os padrões microbiológicos de alimentos e sua aplicação. Disponível em: https://www.in.gov.br/en/web/dou/-/resolucaordc-n-331-de-23-de-dezembro-de-2019-235332272 . Acesso em: 11 de fev.2021.

BRASIL. Ministério da Saúde-MS. Agência Nacional de Vigilância Sanitária - ANVISA. INSTRUÇÃO NORMATIVA N60 DE 23 DE DEZEMBRO DE 2019. Estabelece as listas de padrões microbiológicos para alimentos. Disponível em: https://www.in.gov.br/en/web/dou/-/instrucao-normativa-n-60-de-23de-dezembro-de-2019-235332356. Acesso em: 11 de fev. 2021.

BREGOLIN, J. Cultura de segurança dos alimentos: conceito e elementos para a prática do nutricionista. Universidade Federal do Rio Grande do Sul, Departamento de Nutrição. Porto Alegre, 10 de julho de 2018. Disponível em: <https://www.lume.ufrgs.br/handle/10183/188694>. Acesso em $25 \mathrm{de}$ fev. 2021.

CORREIA, F. et al. Análise bacteriológica de frutos e hortaliças em mercados frutíferos públicos e privados de Juazeiro do Norte-CE. BRASPEN J; vol.32 n.1 p.3-7. Juazeiro do Norte, 2017.

DA SILVA, L. E. S.; CLARO, R. M. Time trends in the consumption of fruits and vegetables among adults in brazilian state capitals and the federal district, 2008-2016. Cadernos de Saude Publica, [s. l.], v. 35, n. 5, p. 2008-2016, 2019. Disponível em: https://doi.org/10.1590/0102-311X00023618

FERREIRA, J. de A. F. Panorama das doenças transmitidas por alimentos no Brasil entre 2000 e 2015 [dissertação]. São Paulo (SP): Universidade de São Paulo, Faculdade de Saúde Pública. [s. l.], p. 78, 2017. 
GANGLIONE, KC. Avaliação Microbiológicos de Hortaliças: A eficácia do sistema de higienização, em uma unidade de alimentação e nutrição. Dissertação (Mestrado Profissional em Vigilância Sanitária). Programa de Pós-Graduação em Vigilância Sanitária, Instituto Nacional de Controle de Qualidade em Saúde. Rio de Janeiro: INCQS/Fiocruz, 2015.

MARINHO, G. A. et al. Perfil Epidemiológico das Doenças Transmitidas por Alimentos e Seus Fatores Causais na Região da Zona da Mata Sul de Pernambuco. UNOPAR Científica, Ciencias Biológicas e da Saúde, [s. l.], v. 17, n. 4, p. 238$243,2015$.

MATOS, L. M; MORETTI, C. L; MOURA, M. A; SILVA, E. Produção segura e Rastreabilidade de hortaliças. Horticultura brasileira, vol. 27 n. 4. 2009. Disponível em: <http://www.scielo.br/scielo.php?script=sci_serial\&pid=01020536\&lng=en\&nrm=iso >. Acesso em: $12 \mathrm{de} \mathrm{fev.} 2021$.

MELO, E. S. de et al. Doenças transmitidas por alimentos e principais agentes bacterianos envolvidos em surtos no Brasil. Pubvet, [s. l.], v. 12, n. 10, p. 1-9, 2018. Disponível em: https://doi.org/10.31533/pubvet.v12n10a191.1-9

MENESES M. F; GRANDA, E. A. Listeria em alimentos minimamente processados. Hig. Alim. Vol. 27 p. 84-92. Pelotas 2013. Disponível em: < https://scholar.google.com.br/scholar?hl=pt-

BR\&as_sdt $=0 \% 2 \mathrm{C} 5 \& \mathrm{q}=$ Listeria+em+alimentos+minimamente+processados. $\& b \operatorname{tnG}=\# d=$ gs_qabs\&u=\%23p\%3Dh-ID5dLTwA0J>. Acesso em: $08 \mathrm{de} \mathrm{fev.}$ 2021.

MONTEIRO, B. D. A. Valor Nutricional De Partes Convencionais e Não convenionais de frutas e hortaliças. Dissertação de Mestrado-Universidade Estadual Paulista (UNESP). Botucatu-São Paulo, p. 68, 2009.

OBARA, T. Qualidade na indústria de alimentos: contexto atual e oportunidades. Monografia (Especialização em Engenharia da Qualidade)-Universidade Tecnológica Federal do Paraná. Ponta Grossa, 2018. Disponível em:< http://riut.utfpr.edu.br/jspui/handle/1/23214>. Acesso em: 24 de fev. 2021.

OLIVEIRA, A.; et al. Doenças transmitidas por alimentos, principais agentes etiológicos e aspectos gerais: uma revisão foodborne diseases, main etiologic agents and general aspects: a review. rev HCPA, [s. l.], v. 30, n. 3, p. 279-285, 2010. Disponível em: https://www.lume.ufrgs.br/handle/10183/157808.

OLIVEIRA, M. A. C. de; MENDONÇA, M. de S.; CORDEIRO, C. A. M. Estudo de caso cas BPF e Análise de Implantação do Sistema APPCC em uma Unidade de Beneficiamento de Polpa de Frutas. [s. l.], p. 329-345, 2020. Disponível em: https://doi.org/10.37885/200801015

SANTOS, R. et al. Qualidade microbiológica de alimentos in natura minimamente processados. Global science and technology, Rio verde, v.12, n.01, 2019. 
<https://www.academia.edu/download/59498506/qualidade_microbiolog ica_de_alimentos_in_natura_minimamente_processados20190603-83261c5jmbp.pdf>. Acesso em 12 de fev. 2021

SÃO JOSÉ, J. F. B. Estratégias alternativas na higienização de frutas e hortaliças. Revista de Ciências Agrárias, [s. l.], v. 40, n. 3, p. 630-640, 2016. Disponível em: https://doi.org/10.19084/rca16124

SÃO JOSÉ, J. F. B. et al. Ocorrência de patógenos em frutas e hortaliças. Revista Higiene Alimentar [s. l.], v. 28. p. 96-101, 2014.

SOUSA, S. M. Análise das condições higiênico-sanitárias das frutas e hortaliças comercializadas no mercado municipal e em uma feira livre da cidade de Capanema, Pará. Trabalho de Conclusão de Curso (Graduação em Ciências Biológicas bacharelado) - Universidade Federal Rural da Amazônia, Campus Capanema (PA), 2017. Disponível em:< https://scholar.google.com.br/scholar?hl=pt-

BR\&as_sdt=0\%2C5\&q=principais+bacterias+patogenicas+em+frutas+e+hor tali\%C3\%A7as+2017\&btnG=\#d=gs_qabs\&u=\%23p\%3D3wU5spAFeLgJ>. Acesso em: 22 de fev. 2021.

SOUZA, M. Doenças Transmitidas por Alimentos no Brasil: uma revisão de literatura. Trabalho de colisão de Curso (Bacharel em Farmácia), Centro Universitário São Lucas, Ji-Paraná- Rondônia, 2019. Disponível em <http://repositorio.saolucasjiparana.edu.br:8080/bitstream/123456789/1 82/1/Micaelle\%20Gon\%C3\%A7alves\%20de\%20Souza\%20\%20Doen\%C3 \%A7as\%20transmitidas\%20por\%20alimentos\%20no\%20Brasil\%20\%20u ma\%20revis\%C3\%A3o\%20de\%20literatura.pdf>. Acesso em $25 \mathrm{de} \mathrm{fev.} \mathrm{de}$ 2021.

TEIXEIRA, L. E. B. et al. Qualidade microbiológica de frutas e hortaliças comercializadas na cidade de Juazeiro do Norte - CE. Revista Verde de Agroecologia e Desenvolvimento Sustentável, [s. l.], v. 8, n. 3, p. 23-26, 2013.

TONDO, E. C. et al. Avanços da segurança de alimentos no Brasil. Vigilância Sanitária em Debate, $\left[\begin{array}{ll}s . & l .\end{array}\right]$, v. 0 , n. 0 , 2015. Disponível em: https://doi.org/10.3395/2317-269x.00443

VINHOLIS, M. de M. B.; AZEVEDO, P. F. de. Segurança do alimento e rastreabilidade: o caso BSE. RAE eletrônica, [s. l.], v. 1, n. 2, p. 02-19, 2002. Disponível em: https://doi.org/10.1590/s1676-56482002000200008

SPERS, E. E.; ZYLBERSZTAJN, D.; LAZZARINI, S. G. Percepção do Consumidor sobre os Mecanismos de Qualidade e Segurança em Alimentos. Revista de Administração da Unimep, [s. l.], v. 1, n. 1, p. 57-80, 2003. Disponível em: https://doi.org/10.15600/1679-5350/rau.v1n1p57-80 
ROUGEMONT, J. A. Alimentos seguros - necessidade ou barreira comercial? Perspectivas Online,[s. l.].. v.1, n.2, p.62-70, 2007. Disponível em <file:///C:/Users/cliente/Downloads/254-Texto\%20do\%20artigo-691-110-20140627.pdf> Acesso em: 15 fev. 2021. 


\title{
CAPÍTULO II
}

\section{IMPORTÂNCIA DAS PRÁTICAS DE HIGIENIZAÇÃO DE FRUTAS E HORTALIÇAS NO AMBIENTE DOMICILIAR}

DOI: 10.51859/amplla.asf566.1121-2

\author{
Marina Passos Raul ${ }^{1}$ \\ Natália das Neves Leite ${ }^{1}$ \\ Larissa de Oliveira Silva ${ }^{1}$ \\ Hiolanda de Negreiros Magalhães ${ }^{1}$ \\ Simone Kelly Rodrigues Lima ${ }^{2}$
}

\footnotetext{
1 Graduanda do Curso de Tecnologia de Alimentos. Instituto Federal de Educação, Ciência e Tecnologia do Maranhão - IFMA/Campus Bacabal

${ }^{2}$ Mestra em Alimentos e Nutrição. Docente do Curso de Tecnologia de Alimentos. Instituto Federal de Educação, Ciência e Tecnologia do Maranhão - IFMA/Campus Bacabal
}

\section{RESUMO}

As doenças desenvolvidas no contexto da alimentação ainda representam um importante problema de saúde pública, em um panorama mundial em que as falhas nas medidas de higiene têm contribuído de forma significativa na propagação e agravos na saúde da população, o que tem levado a uma ampla discussão acerca desse tema. Este artigo, através de uma revisão, traz uma abordagem sobre os potenciais riscos de contaminação de frutas e hortaliças pelos patógenos responsáveis pela maioria dos surtos de origem alimentar. O levantamento abrange os principais micro-organismos encontrados em frutas e hortaliças, assim como os principais sintomas e período de incubação. Conta ainda com as principais orientações acerca das recomendações para higienização/sanitização de frutas e hortaliças que podem ser realizadas em ambiente domiciliar, a fim de garantir um alimento seguro para consumo.

Palavras-chave: Hortifrutis. Surtos alimentares. Higiene. Sanitização.

\section{INTRODUÇÃO}

Segundo a Organização Mundial da Saúde (2021), existem mais de 250 tipos de doenças transmitidas por alimentos e/ou água contaminada (DTAs). Grande parte dessas contaminações ocorrem no ambiente domiciliar. A maioria dessas doenças são causadas por bactérias, vírus e outros parasitas, sendo um potencial perigo principalmente para os alimentos consumidos crus, e desta forma, apresentando-se como um grande problema em nível mundial para a saúde pública. 
Desde que se instalou o cenário de pandemia e o crescente aumento no número de casos da doença, passou-se a ter uma preocupação maior com as práticas de higiene, inclusive no contexto da alimentação. Essa situação de incerteza e temores de agravos na saúde, chamaram a atenção para práticas sanitárias simples, mas que há muito tempo têm sido negligenciadas principalmente nos domicílios, e, com isso, ocasionado inúmeros registros de surtos alimentares. Mesmo não havendo qualquer evidência de que o vírus SARS- CoV-2 possa ser transmitido pelo consumo de alimentos, houve uma mudança na rotina de higiene com os alimentos, já que estudos mostraram a possibilidade da permanência do vírus nas superfícies, que da mesma forma que outros microorganismos, podem passar a circular no ambiente através de contaminação cruzada quando as boas práticas de higiene e manipulação são desconsideradas. Desta forma, é importante ressaltar que os processos de higienização merecem especial atenção para a manutenção de um alimento seguro para consumo, não somente para a prevenção da disseminação do Coronavírus, mas também, para a prevenção de qualquer outro agente contaminante cujo os reflexos para a saúde pública merecem especial atenção (LIMA et al, 2020; OLIVEIRA et al, 2020; BRASIL, 2020).

A contaminação por agentes patogênicos ocorre principalmente por ineficiência das condições higiênico sanitárias, principalmente em alimentos que não passarão por qualquer outra etapa ou processamento que elimine ou reduza a contaminação a níveis aceitáveis antes do consumo, a exemplo de frutas e hortaliças, que normalmente são consumidas cruas (SORAGNI et. al, 2019).

Segundo o ministério da saúde (2020) os dados da análise epidemiológica de doenças transmitidas por alimentos mostram que 38,4\% dos surtos causados por agentes microbiológicos ocorrem no próprio domicílio, ocasionados principalmente por práticas higiênicas deficientes no pré-preparo e preparo dos alimentos. Mas esse dado não reflete apenas a realidade do Brasil. De acordo com a Europen Food Safety Authority (EFSA), na União Européia, até 95\% dos casos de intoxicação alimentar tem origem nas residências. Já na Nova Zelândia, dos surtos de gastroenterite, cerca de 39,3\% dos casos notificados foram adquiridos em casa (DEON et al, 2014)

Os hábitos de higiene praticados em casa, contribuem efetivamente no aumento dos índices de doenças transmitidas por alimentos (WHO, 2021). Ao 
contrário do que se imagina, quando comparados com serviços alimentícios fora do lar, a maioria dos casos de intoxicação alimentar são devidos a pequenos focos que se originam nos domicílios, e por esse motivo, o estudo das práticas que culminam com estes resultados são de extrema relevância (REDMOND, GRIFFITH, 2009; EFSA, 2011). Embora este tema seja de extrema importância no âmbito da saúde pública, ainda existe uma lacuna na literatura sobre a relevância do ponto de vista teórico e contextual das práticas de higiene que ocorrem nos domicílios direcionadas aos hortifrutis (OLIVEIRA et al. 2020).

Dessa maneira, este estudo teve o objetivo de fazer um levantamento sobre a relação entre práticas de higiene em frutas e hortaliças nas residências e os riscos de contaminação por agentes patógenos.

\section{PRÁTICAS DOMICILIARES E O PAPEL DA HIGIENIZAÇÃO DE}

\section{FRUTAS E HORTALIÇAS NA PREVENÇÃO DOS SURTOS} ALIMENTARES

Segundo a Organização Mundial de Saúde (2020), existe a estimativa de que aproximadamente 2,2 milhões de pessoas morrem ao ano por doenças transmitidas por alimentos. Sua ocorrência cresce todos os anos, embora muitas dessas mortes pudessem ser evitadas por meio de práticas adequadas de higiene (MAKUN, 2016). Frutas e hortaliças são produtos que podem ser facilmente contaminados nas diferentes fases de produção, desde o plantio até a mesa do consumidor. Esta contaminação pode ser ainda mais severa quando medidas de controle como Boas Práticas de Fabricação (BPF), que visam garantir a qualidade do produto final e minimizar os riscos de contaminação microbiológica, são ignoradas (BRASIL,2020).

Os sintomas da contaminação por microrganismos podem variar de pessoa para pessoa, assim como o períodopara aparecimento dos primeiros sintomas, que dependem do tipo e tempo de incubação do microrganismo. As complicações na saúde podem variar de leve a severa, em alguns casos podendo levar ao óbito ou incapacidade em poucos dias. Por esse motivo, é de fundamental importância evitar a contaminação em todas as fases do processo (FERNANDES et al, 2015). Os microrganismos apresentam diferentes períodos de incubação, sinais e sintomas (Tabela 1). 
Tabela 1-Principais microrganismos encontrados em frutas e hortaliças

\begin{tabular}{|c|c|c|c|}
\hline Microrganismos & Sintomas & $\begin{array}{l}\text { Período de } \\
\text { incubação }\end{array}$ & Referências \\
\hline Salmonella spp. & $\begin{array}{l}\text { Dores abdominais, diarreia, } \\
\text { calafrios, febre alta, náuseas } \\
\text { e septicemia. }\end{array}$ & 7 a 21 dias & $\begin{array}{l}\text { (SHINOHARA, } \\
\text { 2008). }\end{array}$ \\
\hline $\begin{array}{c}\text { Listeria } \\
\text { Monocytogenes }\end{array}$ & $\begin{array}{l}\text { Febre alta, tremores, dor de } \\
\text { cabeça grave, rigidez no } \\
\text { pescoço e náuseas. }\end{array}$ & 7 a 60 dias & $\begin{array}{l}\text { (SILVA et al., } \\
\text { 2016). }\end{array}$ \\
\hline Escherichia coli & $\begin{array}{l}\text { Cólicas abdominais severas, } \\
\text { diarreia (em alguns casos } \\
\text { com sangue), náuseas, } \\
\text { vômito, febre, calafrios, } \\
\text { mialgia }\end{array}$ & 3 a 4 dias & $\begin{array}{l}\text { (CALDORIN et } \\
\text { al., 2013). }\end{array}$ \\
\hline $\begin{array}{c}\text { Staphylococcus } \\
\text { aureus }\end{array}$ & $\begin{array}{l}\text { Náusea, vômito, dor de } \\
\text { cabeça, dor abdominal, e } \\
\text { diarreia. Dor muscular e } \\
\text { prostração podem ser } \\
\text { observados em vários casos. }\end{array}$ & $\begin{array}{c}30 \text { min a } 8 \mathrm{~h} \\
\text { (média de } 2 \text { a } 4 \mathrm{~h} \text { ) }\end{array}$ & $\begin{array}{l}\text { (SILVA et al., } \\
\text { 2017). }\end{array}$ \\
\hline Vírus hepatite A & $\begin{array}{l}\text { Febre, mal-estar, anorexia, } \\
\text { náuseas, dores abdominais e } \\
\text { icterícia. }\end{array}$ & $\begin{array}{c}10 \text { a } 50 \text { dias } \\
\text { (média } 30 \text { dias) }\end{array}$ & $\begin{array}{l}\text { (PEREIRA; } \\
\text { GONÇALVES, } \\
\text { 2003; NUNES et } \\
\text { al., 2010). }\end{array}$ \\
\hline Giárdia & $\begin{array}{l}\text { Diarréia (pode durar de dias } \\
\text { a semanas) infecções } \\
\text { crônicas (pode durar meses) }\end{array}$ & $\begin{array}{c}1 \text { a } 3 \text { semanas } \\
\text { (média de } 7 \text { a } 10 \\
\text { dias) }\end{array}$ & $\begin{array}{l}\text { (MARCIANO, } \\
\text { 2019). }\end{array}$ \\
\hline Cryptosporidium & $\begin{array}{l}\text { Cólicas abdominais, diarreia, } \\
\text { enjoo, vômito, febre e } \\
\text { fraqueza. }\end{array}$ & 2 a 14 dias & $\begin{array}{l}\text { (CHIUCHETTA, } \\
\text { 2010; } \\
\text { MARCIANO, } \\
2019 \text { ). }\end{array}$ \\
\hline Cyclospora & $\begin{array}{l}\text { Diarreia líquida, evacuação } \\
\text { explosiva, náuseas, anorexia, } \\
\text { flatulência, dor abdominal, } \\
\text { dores musculares e fadiga. }\end{array}$ & $\begin{array}{c}\text { Aproximadamente } \\
\text { uma semana }\end{array}$ & $\begin{array}{l}\text { (EDUARDO, } \\
\text { 2008; } \\
\text { MARCIANO, } \\
\text { 2019). }\end{array}$ \\
\hline
\end{tabular}


Práticas de manipulação de alimentos nas residências propiciam o crescimento microbiano. Estudos sobre condições higiênico-sanitárias de manipuladores têm se mostrado um perfil frequentemente inaceitável com relação à contaminação microbiana encontrada em diversos sítios anatômicos como nariz e boca (DEON et al, 2014). A manipulação continua sendo a principal via de contaminação e ocorre principalmente pelo contato direto do alimento com mãos e utensílios mal higienizados, sendo este um ponto crítico principalmente em ambientes onde se realiza o preparo de alimentos que serão consumidos crus (TODD et al., 2010).

A maioria dos responsáveis pela manipulação de alimentos nos domicílios nunca recebeu qualquer orientação sobre manipulação segura de alimentos, isso reflete uma situação em que a maioria das pessoas que preparam alimentos nas residências têm noções básicas de segurança conforme o acesso à informação e à escolaridade, embora nem sempre a prática esteja associada ao comportamento. Um dos principais estudos americanos sobre segurança alimentar, mostrou que $66 \%$ das pessoas que manipulam alimentos não lavavam as mãos antes de iniciar a atividade, $41 \%$ não lavam vegetais e $60 \%$ usavam uma única tábua para todas as tarefas de corte (WILCOCK et al, 2004).

Em estudo realizado por Bressa e Oliveira (2020), foi retratado que manipuladores têm o hábito de manter contato com os alimentos portando unhas compridas e/ou com esmalte, além de fazer o uso de adornos pessoais, entre outros hábitos que aumentam as chances de uma contaminação cruzada. É evidente que existe uma falta de conhecimento por parte desses indivíduos em relação a estas questões, tanto de higiene pessoal, como também do próprio ambiente, principalmente em relação às residências, cujo estudo mostrou que é comum a presença de animais domésticos circulando, e que estes, mesmo aparentemente saudáveis, podem ser portadores assintomáticos de diferentes microrganismos patogênicos.

\section{RECOMENDAÇÕES PARA HIGIENIZAÇÃO DE FRUTAS E HORTALIÇAS NAS RESIDÊNCIAS}

Para que a ingestão vegetais seja uma prática segura do ponto de vista biológico, os processos de higiene são previamente necessários, no entanto, não 
basta apenas que eles sejam realizados, acima de tudo, deve-se garantir que eles sejam corretamente executados para que se obtenha um resultado efetivo para a segurança do consumo. Além da limpeza, uma etapa de sanitização normalmente é necessária. Nesta perspectiva, é importante destacar a diferença entre os termos limpeza e sanitização: a limpeza tem por objetivo a retirada de sujidades de diferentes naturezas aderidos à superfície do produto. Por outro lado, a sanitização, refere-se a um processo que deve ser realizado após a limpeza, com uso de agentes químicos ou físicos que visam a destruir os micro-organismos remanescentes no vegetal (KRINGEL et al, 2016).

Dessa forma, o processo de higienização das frutas e hortaliças deve ser realizado assim que o alimento chegar ao domicílio. Deve-se começar com uma lavagem para retirar as sujidades maiores que possam estar aderidas à superfície. Em caso de folhosos, primeiramente, deve-se realizar uma seleção prévia com a seleção e descarte das folhas com danos aparentes. Em relação a frutas e hortaliças frágeis é indicada apenas a utilização da força da água corrente para realizar a retirada de sujidades. No entanto, se estes alimentos possuírem envoltórios ou estruturas mais resistentes, pode ser favorável à realização da limpeza com a mão ou com o auxílio de uma escova macia para esfregar suas superfícies (EMBRAPA, 2020).

Para frutas e hortaliças que serão consumidas cruas e com casca é recomendado que seja realizada a sanitização. 0 processo de sanitização de frutas e hortaliças é feito pela imersão das mesmas em um recipiente com água, e, a partir daí, é adicionado um saneante. Esse processo é responsável por diminuir a quantidade de microrganismos. A água usada deve ser potável e o recipiente limpo. Também é necessário escolher um sanitizante com indicação para esta finalidade, os quais podem ser facilmente encontrados em supermercados. Embora existam muitas possibilidades de produtos, é importante que no momento da compra seja observado se o mesmo possui registro da Vigilância Sanitária. É imprescindível que, além do registro, sejam seguidas as orientações sobre as diluições e cuidados necessários à utilização (DAMASCENA,2017).

Os sanitizantes apropriados para as frutas e hortaliças são aqueles que contêm cloro em sua composição. Nas residências é comum a utilização de hipoclorito de sódio, popularmente comercializado como água sanitária (de 2,0 a 
2,5\% de cloro ativo), no entanto, essa indicação deve vir na embalagem do produto e com a devida comprovação de que não está presente na composição outros tipos de aditivos que impeçam sua utilização na sanitização de frutas e hortaliças, como por exemplo, corantes, fragrâncias ou sequestrantes, dentre outros. É importante ressaltar que o enxágue ao final do processo é uma etapa necessária, e para isso, deve-se fazer a utilização de água potável (CASTRO et al, 2013).

Para os alimentos comprados embalados, sugere-se fortemente a lavagem da embalagem com água e sabão ou desinfecção com álcool 70\%. Estes cuidados com alimentos embalados são necessários para evitar a propagação da contaminação cruzada (FIOCRUZ, 2020).

Figura 1- Etapas para higienização/sanitização de hortifrútis consumidos com casca e sem casca no ambiente domiciliar

\section{SELEÇÃO}

Observara presença de injúrias e no caso de folhosos, fazer a remoção e descarte das folhas com danos aparentes.

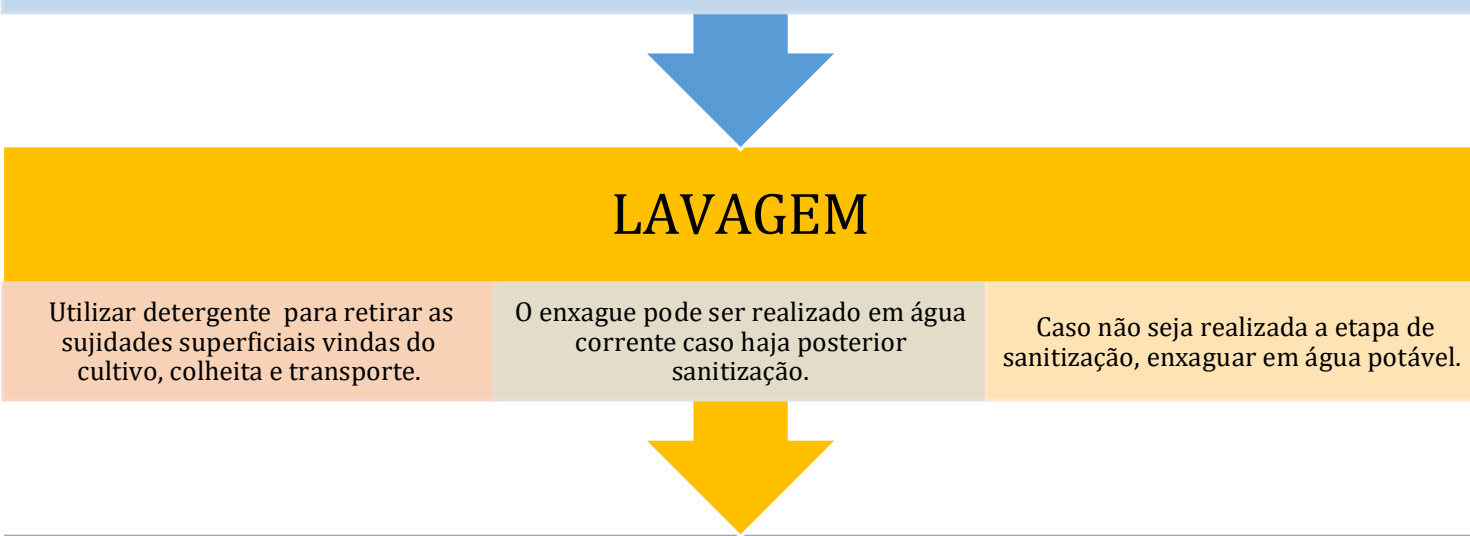

\section{SANITIZAÇÃO}

Utilizar soluções cloradas (hipoclorito de sódio com concentração de $2-2,5 \%$ de cloro ativo).

Dosagem caseira: uma colher de sopa para cada 1 litro de água.
Tempo de imersão na solução por 15 minuto

\section{SECAGEM}


Alguns cuidados para a manutenção da qualidade do produto devem ser considerados ao final das etapas de higienização, como a drenagem da água após a sanitização, com a finalidade de eliminar o máximo possível de umidade. 0 excesso de água em hortaliças embaladas, por exemplo, pode contribuir para a diminuição da sua vida útil. Com relação ao processo de secagem, é recomendado que ocorra em temperatura ambiente (EMBRAPA, 2020)

\section{CONSIDERAÇÕES FINAIS}

As doenças transmitidas por alimentos vêm sendo um desafio para a saúde pública há muito tempo. Embora a importância dos processos de higiene tenham ganhado destaque desde o surgimento da pandemia por COVID-19, onde as boas práticas de higiene se tornaram peça fundamental e essa prática tenha ganhado especial atenção, o que se observa é que os consumidores finais ainda possuem pouco ou nenhum conhecimento sobre a importância da higiene adequada dos alimentos, em especial aos que são consumidos crus como as frutas e hortaliças. Aliados a isso, a mitificação de que a alimentação no lar é sempre uma prática segura deve ser revista, visto a importância epidemiológica dos surtos que tem como origem os domicílios.

\section{REFERÊNCIAS}

BRASIL, Embrapa,2020. Sanitização: cuidados na hora de preparar as hortaliças. Disponível em: https://www.embrapa.br/hortalica-nao-e-sosalada/sanitizacao .Acesso em: 24 fev. 2021.

BRASIL. Agência de informação Embrapa, 2020. Coronavírus: cuidados na produção, no processamento e no consumo de hortaliças. Disponível em: https://www.embrapa.br/busca-de-

noticias?p_p_id=buscanoticia_WAR_pcebusca6_1portlet\&p_p_lifecycle=0\&p_ p_state=pop_up\&p_p_mode=view\&p_p_col_id=column-

$1 \&$ p_p_col_count=1\&_buscanoticia_WAR_pcebusca6_1portlet_groupId=135 5126\&_buscanoticia_WAR_pcebusca6_1portlet_articleId=51937376\&_busca noticia_WAR_pcebusca6_1portlet_viewMode=print. Acesso em: 10 fev. 2021.

BRASIL. Ministério da Saúde. Distribuição temporal dos surtos notificados de doenças transmitidas por alimentos - Brasil, 2007-2015. Boletim epidemiológico, Brasília, v.51, n.32, p.16-17, ago. 2020. Disponível em: < https://www.gov.br/saude/pt-br/centrais-de-conteudo/boletimepidemiologico-svs-32-pdf/view >. Acesso em: 16 Fev. 2021. 
BRESSAN, E. C.; OLIVEIRA, R. C. Práticas em higiene e manipulação de alimentos no ambiente doméstico de moradores de uma comunidade de Joinville/SC. Redes-Revista Interdisciplinar do IELUSC, n. 2, p. 193-203, 2020.

CALDORIN, M. et al. Ocorrência de Escherichia coli produtora de toxina Shiga (STEC) no Brasil e sua importância em saúde pública. BEPA. Boletim Epidemiológico Paulista (Online), v. 10, n. 110, p. 4-20, 2013.

CASTRO, F. T. et al. Ações de intervenção para promoção do consumo seguro de frutas e hortaliças em pontos de venda da zona oeste do Rio de Janeiro. Oikos: Família e Sociedade em Debate, v. 24, n. 1, p. 004-029, 2013.

CHIUCHETTA, F. A. Criptosporidiose em paciente com espondilite anquilosante usando adalimumabe. Revista Brasileira de Reumatologia, [s. l.], v. 50, n. 3, p. 328-332, 2010. Disponível em: https://doi.org/10.1590/s048250042010000300012

DAMASCENA, A. C. G.; GONÇALVES, A. C. Qualidade microbiológica de alfaces orgânicas e não orgânicas em diferentes regiões do Brasil. [s. l.], 2017. Disponível em: https://bdm.unb.br/handle/10483/18587

DEON, B. C. et al. Perfil de manipuladores de alimentos em domicílios. Ciencia e Saude Coletiva, [s. l.], v. 19, n. 5, p. 1553-1559, 2014. Disponível em: https://doi.org/10.1590/1413-81232014195.04892013

EDUARDO, M. B. de P. et al. Primeiro surto de Cyclospora cayetanensis investigado no Brasil, ocorrido em 2000, no município de General Salgado (SP), e medidas de controle. BEPA. Boletim Epidemiológico Paulista (Online), v. 5, n. 49, p. $05-11,2008$.

EUROPEAN FOOD SAFETY AUTHORITY. The European Union Summary Report on Trends and Sources of Zoonoses, Zoonotic Agents and Food-borne Outbreaks in 2009. EFSA Journal, v. 9, n. 3, p.2090, 2011.

FERNANDES, A.; GUIMARÃES, M. P. S; FERNANDES, S. A. Cartilha sobre Aperfeiçoamento em Boas Práticas de Manipulação e Conservação de Alimentos. Universidade Federal de Minas Gerais. Belo Horizonte, 2015.

FUNDAÇÃO OSWALDO CRUZ (Fiocruz), Ministério da Saúde (Brasil) 2020. Quais as orientações para higienização de alimentos para prevenir a Covid 19?. Disponível em: https://portal.fiocruz.br/pergunta/quais-orientacoes-parahigienizacao-de-alimentos-para-prevenir-covid-19. Acesso em: $24 \mathrm{de}$ fev de 2021.

KRINGEL, A. L. et al. Oficina de alimentação saudável em escolas públicas: relato de dois casos. [s. l.], p. 42-53, 2016. 
LIMA, S. K. R. et al. Impactos Da Covid-19 No Controle Higiênico-Sanitário No Setor Alimentício. Brazilian Journal of Development, [s. l.], v. 6, n. 7, p. 5341453442, 2020. Disponível em: https://doi.org/10.34117/bjdv6n7-838

MAKUN, H. (Ed.). Significance, Prevention and Control of Food Related Diseases. BoD-Books on Demand, 2016.

MARCIANO, M. A. M. Pesquisa de Giardia spp., Cryptosporidium spp., Toxoplasma gondii e Cyclospora cayetanensis em água para consumo humano. Tese de Doutorado. Universidade de São Paulo.

NUNES, H. M. et al. Prevalência de infecção pelos vírus das hepatites A, B, C e D na demanda de um hospital no Município de Juruti, oeste do Estado do Pará, Brasil. 2010.

OLIVEIRA, T. C.; ABRANCHES, M. V.; LANA, R. M. Food (in)security in Brazil in the context of the SARS-CoV-2 pandemic. Cadernos de Saude Publica, [s. l.], v. 36, n. 4, 2020. Disponível em: https://doi.org/10.1590/0102$311 \times 00055220$

ORGANIZAÇÃO MUNDIAL DA SAÚDE. Doenças transmitidas por alimentos: causas sintomas, tratamento e prevenção, brasília, 2021. Disponível em: < https://antigo.saude.gov.br/saude-de-a-z/doencas-transmitidas-poralimentos\#: :text=doen\%c3\%a7as\%20transmitidas\%20por\%20alimentos \%20 d dta,toxinas $\% 2 \mathrm{c} \% 20 \mathrm{v} \% \mathrm{c3} \%$ adrus $\% 20 \mathrm{e} \% 20$ outros $\% 20$ parasitas $>$. Acesso em: 10 fev. 2021

PEREIRA, F. EL; GONÇALVES, C. S. Hepatite A. Revista da Sociedade Brasileira de Medicina Tropical, v. 36, n. 3, p. 387-400, 2003.

REDMOND, E. C .; GRIFFITH, C. J. A importância da higiene na cozinha doméstica: implicações no preparo e armazenamento de alimentos e fórmulas infantis. Perspectivas em Saúde Pública , v. 129, n. 2, pág. 69-76, 2009.

SHINOHARA, N. K. S. et al. Salmonella spp., important pathogenic agent transmitted through foodstuffs. Ciencia e Saude Coletiva, [s. l.], v. 13, n. 5, p. 1675-1683, 2008. Disponível em: https://doi.org/10.1590/s1413-81232008000500031

SILVA, H. R. et al. Listeriose: uma doença de origem alimentar pouco conhecida no Brasil. Higiene Alimentar, [s. l.], v. 30, n. 262-263, p. 17-20, 2016.

SILVA, J. F. M; FEITOSA, A. C; RODRIGUES, Rosimeire Mendes. Staphylococcus aureus em alimentos. DESAFIOS-Revista Interdisciplinar Da Universidade Federal Do Tocantins, v. 4, n. 4, p. 15-31, 2017.

SILVA, T. G. Manipulação, higienização e sanitização doméstica de frutas e hortaliças visando o aumento de vida útil. Boletim Técnico IFTM, n. 2, p. 10-13, 2016. 
SORAGNI, L.; BARNABE, A. S.; DE CAMPOS MELLO, T. R. Doenças transmitidas por alimentos e participação da manipulação inadequada para sua ocorrência: uma revisão. Estação Científica (UNIFAP), v. 9, n. 2, p. 19-31,

TODD, E. C. D. et al. Outbreaks where food workers have been implicated in the spread of foodborne disease. Part 8. Gloves as barriers to prevent contamination of food by workers. Journal of Food Protection, [s. l.], v. 73, n. 9, p. 1762-1773, 2010. Disponível em: https://doi.org/10.4315/0362028X-73.9.1762

WILCOCK, A. et al. Consumer attitudes, knowledge and behaviour: A review of food safety issues. Trends in Food Science and Technology, [s. l.], v. 15, n. 2, p. 56-66, 2004. Disponível em: https://doi.org/10.1016/j.tifs.2003.08.004

WORLD HEALTH ORGANIZATION. Segurança Alimentar, 30 april 2020. Disponível em: $\quad$ https://www.who.int/news-room/fact-sheets/detail/food-safety. Acesso em: 24 fev. 2021. 


\section{ALIMENTO SEGURO EM FOCO}

CUIDADOS COM A HIGIENE DE FRUTAS E HORTALIÇAS PARA A PREVENÇÃO DE SURTOS ALIMENTARES
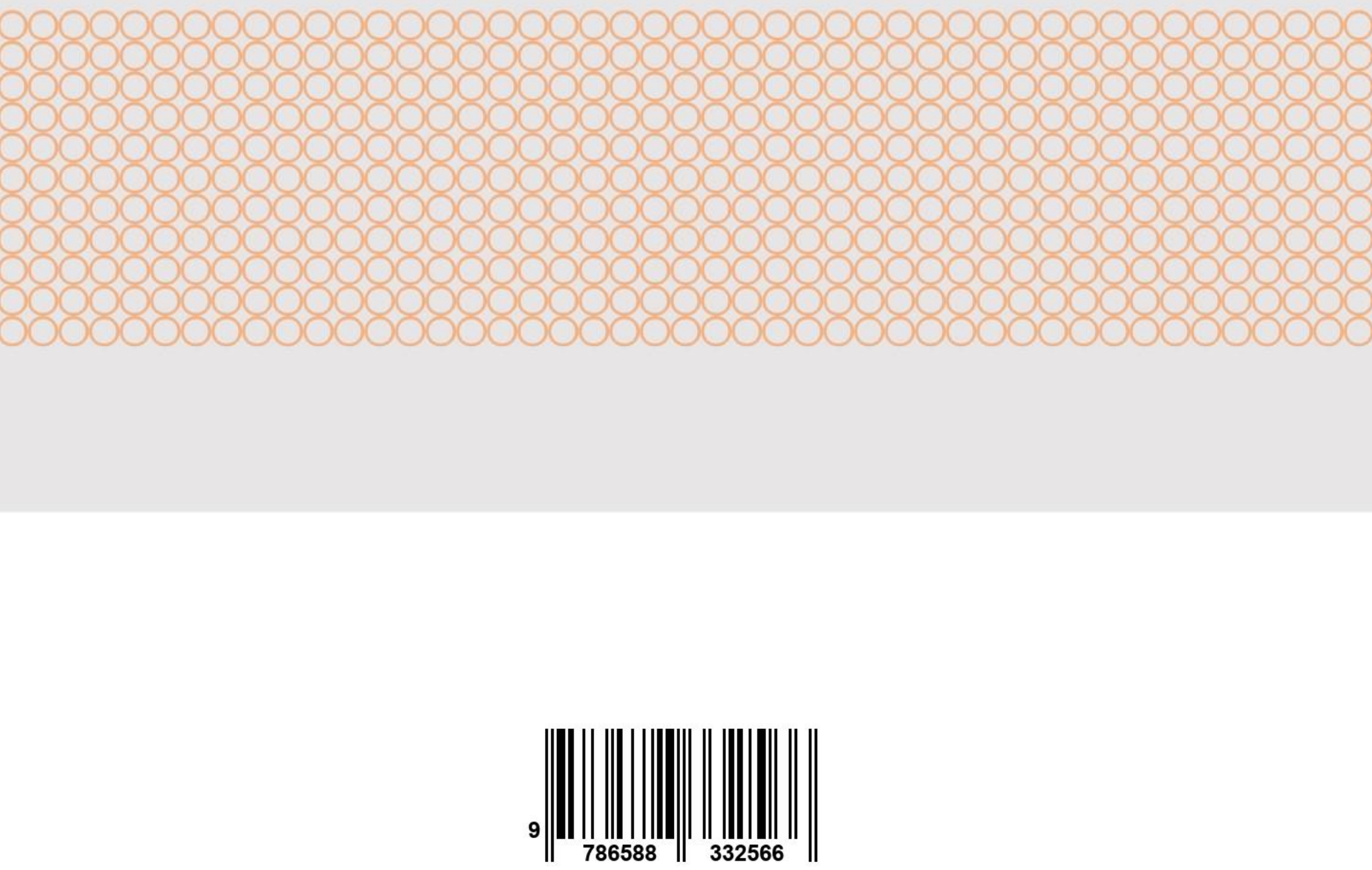